Int. J. Morphol.,

27(4):1099-1104, 2009

\title{
Gross Anatomy of the Heart in the Western Grey Kangaroo (Macropus fuliginosus)
}

\author{
Anatomía Macroscópica del Corazón en el Canguro Gris Occidental (Macropus fuliginosus)
}

Martin Lima; Virginia Méndez \& William Pérez

LIMA, M.; MÉNDEZ, V. \& PÉREZ, W. Gross anatomy of the heart in the Western Grey Kangaroo (Macropus fuliginosus). Int. J. Morphol., 27(4):1099-1104, 2009.

SUMMARY: The aim of this study was provide a description of the macroscopic heart anatomy of the kangaroo Macropus fuliginosus. The terms of the Nomina Anatomica Veterinaria were employed. Heart did not have interventricular sulcus. Auricles were located in both faces of the heart. Right ventricle had slight septomarginal trabecula that extended between papilar muscles and the parietal wall. Right ventricle parietal wall had plenty of trabecula carneae. Septal wall was smooth and had three papilar muscles. Papilar muscles of left ventricle were two and they were located over parietal wall. Septal walls and parietal of left ventricle were full of trabecula carneae that surrounded papilar muscles. Two vessels derived from the aorta, right and left sinus coronary arteries and a septal artery. Septal artery gave irrigation to interventricular septum and derived from left sinus of the aorta and their lumen had a higher diameter than the left coronary artery. Coronary arteries had intra myocardic route.

KEY WORDS: Animal anatomy; Heart anatomy; Zoo animals; Macropus; Coronary vessels.

\section{INTRODUCTION}

Studies in cardiac anatomy in domestic animals are far and well documented in classic text books like Barone (1996). The majority of researches in cardiac anatomy in marsupials are few and not too much detailed (Owen, 1835, 1868; Forbes, 1881; Parsons, 1896; Windle \& Parsons, 1897; Sweet, 1904; Sonntag, 1921; Boardman, 1941; Wood Jones, 1949; Wade, 1968; Dowd, 1969, 1974). Dowd (1974) used early descriptions of the marsupial heart, indicating that none of these accounts were complete and several were results of only a single dissection. One of the most detailed description of a marsupial heart corresponding to a Dowd (1969). In this report Dowd described the heart of Trichosurus vulpecula, a native Australian marsupial. Dowd (1974) described the coronary arteries and veins of Trichosurus vulpecula in 16 hearts. Blair et al. (1942) studied the conducting system in kangaroos and Dowd (1972) in Trichosurus vulpecula. Runciman et al. (1992) in a review summarized the most relevant papers of the anatomy of the marsupial hearts cited in this work.

No study was found describing the detailed cardiac anatomy of Macropus fuliginosus. Since there were no complete descriptions of the gross anatomy of the heart of any kangaroos, it was thought useful to study the most relevant aspects of the heart anatomy in two kangaroos Macropus fuliginosus.

\section{MATERIAL AND METHOD}

The hearts of Western Grey Kangaroos (Macropus fuliginosus) were obtained and dissected from two necropsies of a male and a female from local zoo. The body weight of the male was $60 \mathrm{~kg}$ and $30 \mathrm{~kg}$ in the female. The hearts were studied in fresh and after fixation in a $10 \%$ formaldehyde solution. After studying the external conformation and the distribution of the blood vessels, both ventricles were cut and opened parallel to the coronary and interventricular sulcus, and both auricles were cut at their free border, with the aim of studying the internal conformation. The terms of the NAV (2005) have been used. 


\section{RESULTS}

Heart of Macropus fuliginosus had a globe-shape; red colour Male Kangaroos had a body weight of $291.5 \mathrm{~g}$ and $203.0 \mathrm{~g}$ female. The percentage weight of heart in bodyweight was $0.48 \%$ in male and $0.67 \%$ in female.

The heart was situated in medium mediastinum, with extension until third and sixth rib. It was surrounded by pericardium, fibrous and serum pericardium. Parietal layer of serum pericardium was inseparable of fibrous pericardium. Visceral layer of epicardium was completely bound to the myocardium, no subepicardic fat was found, except in coronary fold. Fibrous pericardium was cover by pericardic pleura. No ligament was found that bound fibrous pericardium to the sternon or to the diaphragm.

Externally two faces were recognizable, two borders, a bottom and an apex. Coronary sulcus was cover in the majority by auricles. Coronary sulcus divided atrium from ventricles. They were no evidence of interventricular paraconal and circumflex sulcus. Deep palpation in the place of sulcus showed the interventricular septum. Right ventricle was situated cranially had thinner wall and was more depressible than left ventricle that had the apex.

Circumference in coronary sulcus was $24.0 \mathrm{~cm}$ en male and $22.0 \mathrm{~cm}$ in female. Distance between left and right ventricular borders was $8.3 \mathrm{~cm}$ in both sexes. Length of coronary sulcus to apex was $10.0 \mathrm{~cm}$ in male and $9.4 \mathrm{~cm}$ in female. The auricles were predominant in auricular face (Fig. 1) but occupied a large space in atrial face (Fig. 2). Right auricle had $4.4 \mathrm{~cm}$ in dorsoventral width in female (Fig. 1) and $7.8 \mathrm{~cm}$ craneo-caudal length, in male $3.2 \mathrm{~cm}$ width and $5.5 \mathrm{~cm}$ length respectively. In female left auricle had $5.5 \mathrm{~cm}$ width and $4.4 \mathrm{~cm}$ length; $5.0 \mathrm{~cm}$ width and $5.8 \mathrm{~cm}$ length in male respectively.

The dorsal part of ventricle (Fig. 1) (Conus arteriosus) had an incurvature to dorsal forming a depression that was cover by a part of the auricles. From this site the pulmonary trunk emerged, and it was no visible directly from the auricular face. Pulmonary trunk had a bulb shape expansion.

Right atrium received blood from both venae cavae and the coronary sulcus; ventrally it had communication with right ventricle through right atrioventricular ostium closed by tricuspid atrioventricular valve. The right auricle had a dense pectinate muscles web going away in every direction and had a thick terminal ridge. Right ventricle had septomarginal trabeculas, with slight development that extended between papillary muscles and the parietal wall. Right ventricle parietal wall had plenty of trabecula carneae. The septal wall was smooth and had three papillary muscles. The s septal wall in distal direction had few trabecula carneae.

Right atrioventricular orifice had $2.0 \mathrm{~cm}$ diameter in female. Pulmonary and tricuspid valves was separated by a supraventricular ridge that measured $1,2 \mathrm{~cm}$ in female and $1.6 \mathrm{~cm}$ in male. Pulmonary valve had three semilunar valves. Right ventricle maximum thickness was $0.4 \mathrm{~cm}$ in medial region in female and $0.8 \mathrm{~cm}$ in male. Left auricle was the most developed part of the left atrium, and had less papillary muscles that right auricle. From each lung three pulmonary veins arrived that merged before get opened in the atrium. Left atrioventricular valve was bicuspid.

Left ventricle (Fig. 3) had a great development of papillary muscles and amount of trabecula carneae. Left ventricle papillary muscles were two and placed over parietal wall. Cranial papillary muscle had $1.9 \mathrm{~cm}$ wide and caudal $1.1 \mathrm{~cm}$ in female. Cranial papillary muscle had three parts of decreased size from cranial to caudal. Between cranial and caudal papillary muscles there was a branching of slight trabecula carneae, probably from conduction system (Fig. 3, arrows). In the parietal wall trabecula carneae occupied the whole wall from the left atrioventricular ostium to the apex.

The septal wall had a dense ramification of trabecula carneae, but near the bottom, the septal wall was smooth. Both papillary muscles were completely surrounded by trabecula carneae (Fig. 3). The trabecula carneae and the divisions of papillary muscles formed a trabecular railing plenty of anfractuosities. Thickness of left ventricle was1.2 $\mathrm{cm}$ in female and $2.3 \mathrm{~cm}$ in male. In addition interventricular septum in middle part was $1.4 \mathrm{~cm}$ in female and $1.7 \mathrm{~cm}$ in male. Beneath the epicardium cardiac nerves and veins were clearly seen, however no arteries could be seen in the surface. Aortic valve had three semilunar valves and the concavity of the arterial face created with aorta the aortic sinus. Right and left coronary arteries and septal artery derived from right and left sinus respectively. The right coronary artery passed trough the coronary sulcus under left auricle and goes down intramiocardic situation to the left ventricle, and crossed the distal part of the vein from atrial face.

The left coronary artery emitted a branch to right auricle and to the infundibulum, modifying route over the parietal wall of right ventricle in intramiocardic situation. The septal artery reach the interventricular septum, and was a direct branch of the aorta emerging from the aortic left sinus by a hole that was greater than the left coronary artery and was situated $0.4 \mathrm{~cm}$ closer to the heart. The coronary sinus hole was situated ventral to the hole of caudal vena cava. 


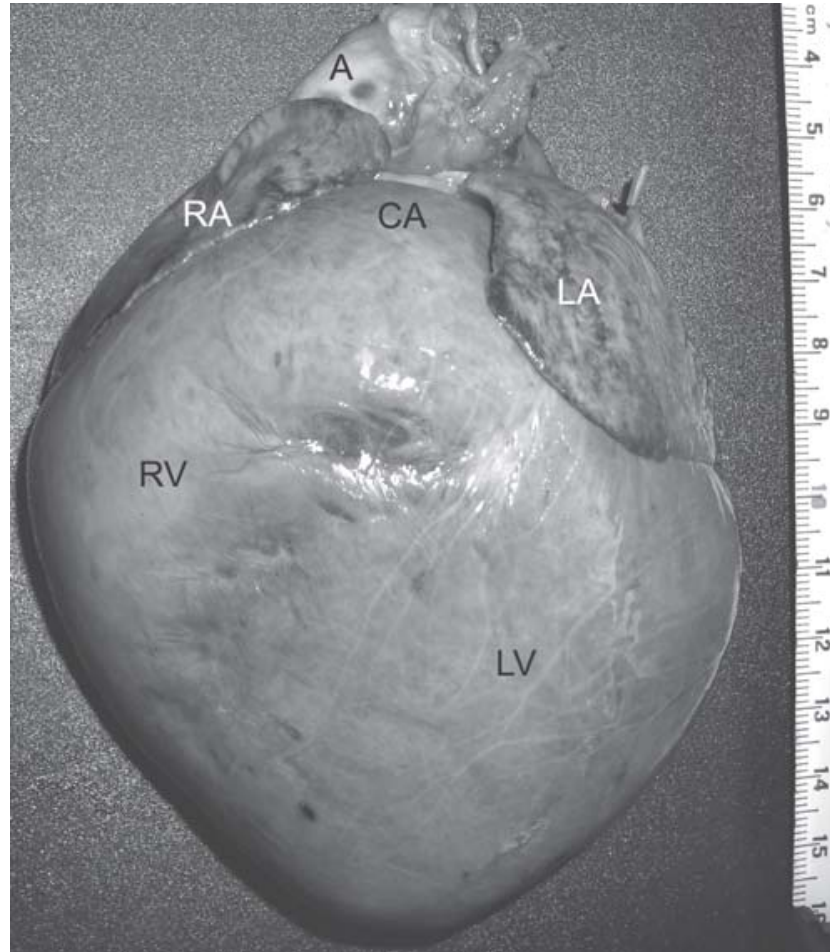

Fig. 1. Auricular face of the female kangaroo heart. LV. Left ventricle. LA. Left auricle. RA. Right auricle; RV. Right ventricle. PT: pulmonary trunk; CA. Conus arteriosus.

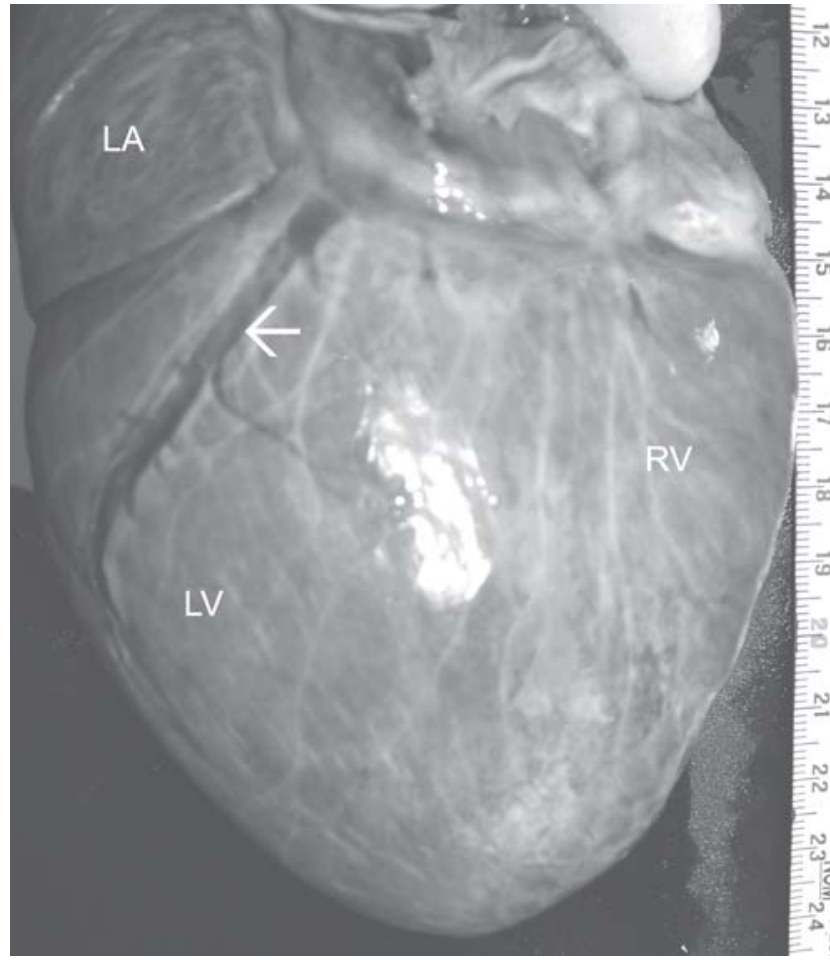

Fig. 2. Atrial face of the male kangaroo heart. LV. Left ventricle; LA. Left auricle; RV. Right ventricle. Arrow: Cardiac vein of atrial face.

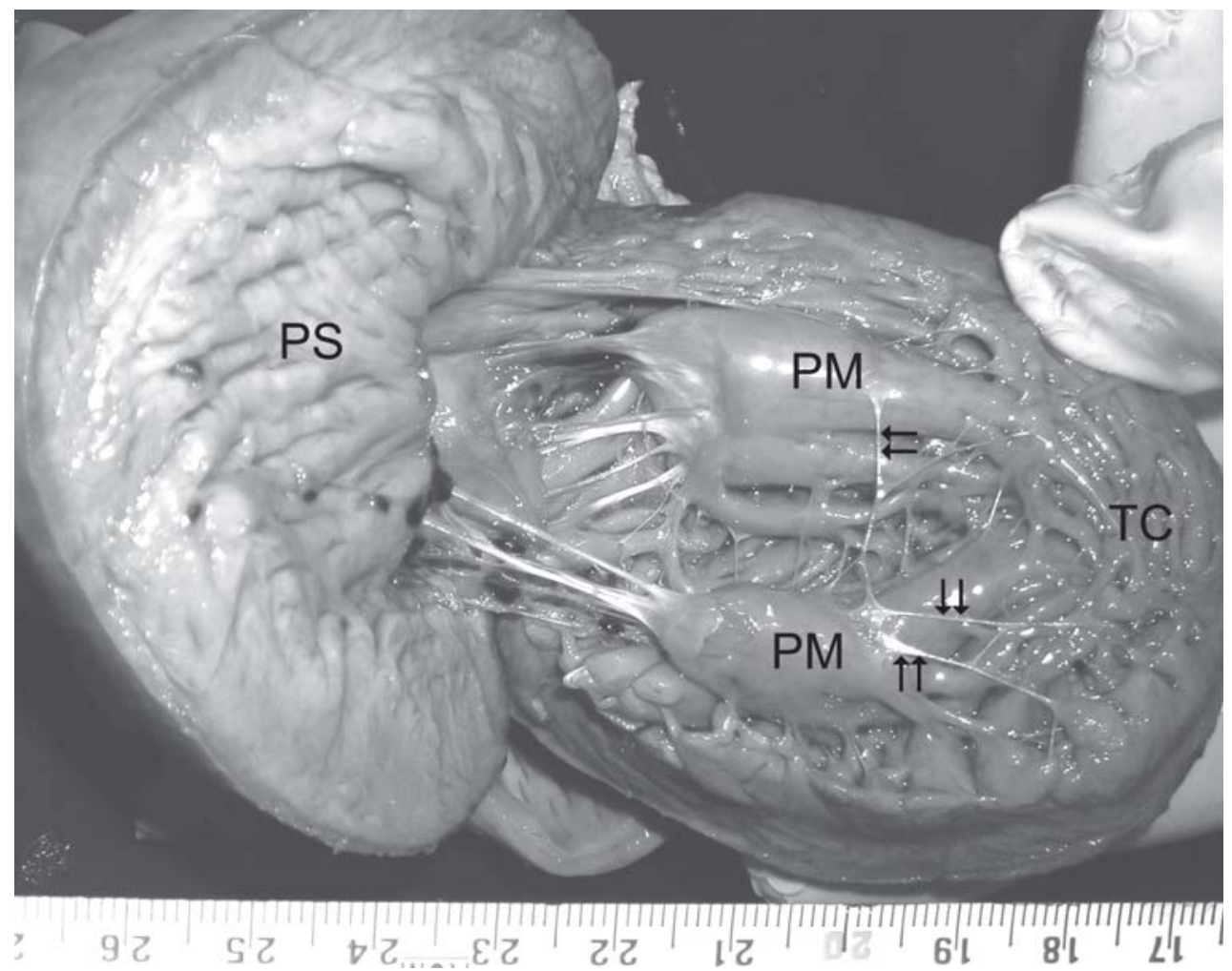

Fig. 3. Interior of the left ventricle. TC. trabecula carneae; PM. papillary muscles. Arrows: muscular strands of conducting system.
The most visible vein in the surface was the subepicardic vein or atrial face vein (Fig. 2) that measured $0.7 \mathrm{~cm}$ length and that was divided in two branches of $0.7 \mathrm{~cm}$ each one; it was the only one in male and it measured $5.0 \mathrm{~cm}$ length and $0.4 \mathrm{~cm}$ width. 


\section{DISCUSSION}

The situation of heart in mediastinum was similar to those indicated in Macropus robustus (Boardman). The relative weight of heart was bigger in female, in contrast to the previous reports in other species (Barone). Both male and female hearts were normal with no evidence of pathology. The globe shape remembered dog's heart. The pericardium had a similar disposition as the domestics mammals (Barone), with the exception of the lack of connection with ligaments or adherences between fibrous pericardium and the sternum or diaphragm. Dowd (1969) described in Trichosurus vulpecula a loose attachment of the pericardium to the cranial two-thirds of the sternum. The most relevant finding in the external part was the absence of interventricular sulcus, subepicardic fat and superficial arteries and the great development of both auricles. These characteristics make different this heart from the others domestic mammals. The absence of interventricular sulcus, arteries and subepicardic fat was reported in Trichosurus vulpecula (Dowd, 1969).

The internal structure of kangaroo heart was very similar to the description for Arctocephalus australis (Pérez et al., 2008), even if they are distant species. Right atrium ok kangaroo did not present any difference to the description for domestics animals (Barone) except for the great development of the auricle.

The right ventricle of Macropus fuliginosus had three papillary muscles localised in the septal wall and distributed in a comparable manner to the one in domestic animals (Barone). In the wombat two papillary muscles were found in right ventricle (Wade) and two to four papillary muscles in the opossum (Wade \& Neely, 1949). In Macropus spp (Owen, 1868) three papillary muscles are cited in the literature and in Macropus rufus two are mentioned (Windle $\&$ Parsons). Among the marsupials, there is a considerable difference in both the number of cusps and the number of papillary muscles. However, all the descriptions of the marsupial's heart agree that no papillary muscles arise from the non-septal (parietal) wall of the right ventricle (Dowd, 1969).

The septomarginal trabecula of the ventricle was more than a few and with slightly development and they presented a different shape compared with the description in other animals (Truex \& Warshaw, 1942; Depreux et al., 1976).

The left atrium was similar but smaller than right atrium, presented a considerable auricular development. Left auricle was bigger than the rest of domestic animals.
In the left ventricle of kangaroo they had two large papillary muscles. In the left ventricle the anterior and posterior papillary muscles were present in $100 \%$ of cases of both human and animal hearts (Ozbag et al., 2005). The shapes of papillary muscles were quite similar in animal hearts, while the variations of shapes of papillary muscles were more established in human hearts (Ozbag et al.). The left ventricle had no septomarginal trabecula, but it had a large amount of slight trabeculas, probably belonging to fibbers of conductive cardiac system extended between the trabecula carneae and the papillary muscles.

Both parietal and septal wall of the left ventricle were full of trabecula carneae, structures that were less abundant in right ventricle. Furthermore in cardiac valves we used terms of the NAV, using names of Valva atrioventricularis dextra and sinistra with Cuspis and Valva trunci pulmonalis and Valva aortae with their semilunares valvulas. The terminology given by the NAV to the cuspids and valves are according to their disposition in Macropus fuliginosus.

In 1926, Grant \& Regnier pointed out that in mammals, blood supply to the heart takes place through two coronary arteries, right and left, arising from the right and left aortic sinuses, respectively (Grant \& Regnier, 1926). Since then, this arrangement is considered to be the normal coronary artery pattern; it is concomitant with the presence of two coronary ostia, right and left. This also happened in this kangaroo; however we must add the presence of a different ostium for the septal artery. The septal artery arose from a separate ostium in $4.8 \%$ of the Syrian hamsters (Duran et al., 2007). It can be concluded that in the two kangaroo studied, the separate origin of the septal artery cannot be considered a coronary anomaly.

In the marsupial hearts, the arteries had intra myocardic localization. In domestic animals and humans, the coronary arteries and their main branches usually lie on the surface of the myocardium. However, they might be found inside the heart muscle in some parts of their trajectories, what is denominated myocardial bridging. Van Nie \& Vincent (1989) defined a "myocardial bridge" (MCB) as an anatomical arrangement in which a sub-epicardial branch of a coronary artery becomes engulfed for a limited segment by myocardial fibres. Myocardial bridges in a number of different species were described and classified (Van Nie \& Vincent). In the marsh deer during their courses in the left and right interventricular grooves, the paraconal and the sub sinuous branches went deep inside the myocardium (Machado et al., 2002). In the Syrian hamsters, both coronary arteries, right and left, become intra myocardic shortly after their origin from the aorta (Duran et al.). 
The anatomical terminology used for the heart in the Nomina Anatomica Veterinaria (2005) can be extrapolated to the heart of Macropus fuliginosus.

In conclusion, the absence of interventricular sulcus, the great development of auricles, the abundant trabecula carneae and the origin and distribution of arterial irrigation and venous irrigation were the most distinguishable characteristics of kangaroo heart. This article describes the cardiac anatomy of Macropus fuliginosus, and is necessary to study other aspects of irrigation, innervation and histological aspects of this organ.

LIMA, M.; MÉNDEZ, V. \& PÉREZ, W. Anatomía macroscópica del corazón en el canguro gris occidental (Macropus fuliginosus). Int. J. Morphol., 27(4):1099-1104, 2009.

RESUMEN: El objetivo de este estudio fue proporcionar una descripción de la anatomía macroscópica de corazón el canguro Macropus fuliginosus. Fueron empleados los términos de la Nomina Anatómica Veterinaria. El corazón no tuvo surco interventricular. Las aurículas se encontraban en ambas caras del corazón. El ventrículo derecho presentó una trabécula septomarginal delgada que se extendía entre los músculos de la pared papilar y parietal. La pared parietal del ventrículo derecho presentó un montón de trabéculas carnosas. La pared septal era lisa y tenía tres músculos papilares. Los músculos papilares del ventrículo izquierdo fueron dos y se encontraron en la pared parietal. Las paredes septal y parietal del ventrículo izquierdo estaban llenas de trabéculas carnosas que rodeaban los músculos papilares. Dos vasos procedentes desde la aorta, arterias del seno coronario derecho e izquierdo, y la arteria septal. La arteria septal dio irrigación al septo interventricular y derivada desde el seno izquierdo de la aorta y su lumen tuvo un mayor diámetro que la arteria coronaria izquierda. Las arterias coronarias presentaron un trayecto intramiocardico.

PALABRAS CLAVE: Anatomía animal; Anatomía del corazón; Animales del zoológico; Macropus; Vasos coronarios.

\section{REFERENCES}

Barone, R. Comparative anatomy of domestic mammals. Angiology. Paris, Vigot, 1996. V. 5.

Blair, D. M.; Davies, F. \& Francis, E. T. B. The conducting system of the marsupial heart. Trans. Roy. Soc. Edin., 60:629-39, 1942.

Boardman, W. On the anatomy and functional adaptation of the thorax and pectoral girdle in the wallaroo (Macropus robustus). Proc. Linn. Soc. NSW., 66:349-87, 1941.

Depreux, R.; Mestdagh, H. \& Houcke, M. Comparative morphology of the septomarginal trabecula in the terrestrial mammals. Anat. Anz., 139:24-35, 1976.

Dowd, D. A. Gross features of the heart of a marsupial, Trichosurus vulpecula. Acta Anat., 74:454-71, 1969.

Dowd, D. A. The conducting system of the heart of a marsupial Trichosurus vulpecula. Acta Anat., 83:204-21, 1972.

Dowd, D. A. The coronary vessels in the heart of a marsupial, Trichosurus vulpecula. Am. J. Anat., 140:47-56, 1974.

Duran, A. C.; Fernandez, M. C.; Fernandez, B.; FernandezGallego, T.; Arque, J. M. \& Sans-Coma, V. Number of Coronary Ostia in Syrian Hamsters (Mesocricetus auratus) with Normal and Anomalous Coronary Arteries. Anat. Histol. Embryol., 36:460-5, 2007.

Forbes, W. A. On some points in the anatomy of the koala (Phascolarctos cinereus). Proc. Zool. Soc.Lond., 18:18095, 1881.

Grant, R. T. \& Regnier, M. The comparative anatomy of the cardiac coronary vessels. Heart, 13:285-317, 1926.

Machado, M. R.; Borges, E. M.; Oliveira, F. S.; FilippiniTomazini, M.; Melo, A. P. F. \& Duarte, J. M. B. Trajeto intramiocárdico das artérias coronárias no cervo-dopantanal (Blastocerus dichotomus). Braz. J. Vet. Res. Anim. Sci., 39:285-7, 2002.

International Committee on Veterinary Gross Anatomical Nomenclature. Nomina Anatomica Veterinaria. 5th ed. 2005.

http://www.wava-amav.org/Downloads/nav_2005.pdf

Owen, R. On the anatomy of Macropus parryi. Benn. Proc. Zool. Soc. London., 1835:152-3, 1835.

Owen, R. On the anatomy of vertebrates, vol. 3: Mammals. London, Longmans, 1868.

Ozbag, D.; Gumusalan, Y. \& Demirant, A. The comparative 
investigation of morphology of papillary muscles of left ventricle in different species. Int. J. Clin. Prac., 59:52936, 2005.

Parsons, F. G. On the anatomy of Petrogale xanthopus, compared with that the others Kangaroos. Proc Zool Soc. Lond., 1896:683-714, 1896.

Pérez, W.; Katz, H. \& Lima, M. Gross heart anatomy of Arctocephalus australis (Zimmerman, 1783). Anat. Sci. Int., 83:6-10, 2008.

Runciman, S. I. C.; Baudinette, R. V. \& Gannon, B. J. The anatomy of the adult marsupial heart: an historical review. Aust. J. Zool., 40:21-34, 1992.

Sonntag, C. F. The comparative anatomy of the koala (Phascolarctos cinereus) and vulpine phalanger (Trichosurus vulpecula). Proc. Zool. Soc. Lond., 192:547-77, 1921.

Sweet, G. Contributions to our knowledge of the anatomy of Notoryctes typhlops, Stirling. Parts I and II. Proc. Roy. Soc. Victoria, 17:76-111, 1904.

Truex, R. C. \& Warshaw, L. J. The incidence and size of the moderator band in man and mammals. Anat. Rec., 82:361-72, 1942.

Van Nie, C. J. \& Vincent, J. G. Myocardial Bridges in Animals. Anat. Histol. Embryol., 18:45-51, 1989.

Wade, O. \& Neely, P. The heart attached vessels of the opossum, a marsupial. J. Mammal, 30:111-6, 1949.

Wade, O. Structural characteristics of the heart of the wombat, Lasiorhinus latifrons Owen. Am. Midl. Nat., 80:266-8, 1968.

Wood Jones, F. A study of a generalized marsupial (Dasycercus cristicauda Kreft). Trans. Zool. Soc. Lond., 26:409-501, 1949.

Windle, B. \& Parsons, F. G. On the Anatomy of Macropus rufus. J. Anat. Physiol., 32:119-34, 1897.
Correspondence to:

William Pérez

Area of Anatomy

Faculty of Veterinary Medicine

University of Uruguay

Lasplaces 1620

11600 Montevideo

URUGUAY

Fax: +59826280130

Email: vetanat@gmail.com

Received: 30-06-2009

Accepted: 22-10-2009 